\title{
Morphological variations of papillary muscles in the mitral valve complex in human cadaveric hearts
}

\author{
Sandhya Arvind Gunnal ${ }^{1}$, MSc Medical Anatomy, Rajendra Namdeo Wabale ${ }^{1}$, MBBS, MD Anatomy,
} Mujeebuddin Samsamuddin Farooqui ${ }^{1}$, MBBS, MD Anatomy

INTRODUCTION Papillary muscle rupture and dysfunction can lead to complications of prolapsed mitral valve and mitral regurgitation. Multiple operative procedures of the papillary muscles, such as resection, repositioning and realignment, are carried out to restore normal physiological function. Therefore, it is important to know both the variations and the normal anatomy of papillary muscles.

METHODS This study was carried out on 116 human cadaveric hearts. The left ventricles were opened along the left border in order to view the papillary muscles. The number, shape, position and pattern of the papillary muscles were observed.

RESULTS In this series, the papillary muscles were mostly found in groups instead of in twos, as is described in standard textbooks. Four different shapes of papillary muscles were identified - conical, broad-apexed, pyramidal and fan-shaped. We also discovered various patterns of papillary muscles.

CONCLUSION No two mitral valve complexes have the same architectural arrangement. Each case seems to be unique. Therefore, it is important for scientists worldwide to study the variations in the mitral valve complex in order to ascertain the reason behind each specific architectural arrangement. This will enable cardiothoracic surgeons to tailor the surgical procedures according to the individual papillary muscle pattern.

Keywords: chordae tendineae, heart, left ventricle, mitral valve complex, papillary muscles

singapore Med J 2013; 54(1): 44-48

\section{INTRODUCTION}

A large proportion of the human population suffers from valvular heart diseases, leading to increased morbidity and mortality. These valvular diseases are most common on the left side. Dysfunction of the papillary muscles and chordae is also frequent. Both papillary muscle rupture and dysfunction can lead to mitral valve prolapse. Many operative procedures involving the papillary muscle, such as resection, repositioning and realignment, are carried out to restore its normal physiological function. Therefore, knowledge of the variations in the normal anatomy of the papillary muscles of the heart is crucial.

\section{METHODS}

A total of 116 formalin-preserved hearts of human cadavers were used in the study. The cadavers from whom the hearts were removed were of unknown age and unknown cause of death. The approximate age of the cadavers was 40-60 years. Hearts with gross morphological variations and those with diseased, fibrosed valves were excluded from the study.

First, the hearts were washed and the cavity of the left ventricle was opened by taking a longitudinal incision along the left border, extending from the left auricle to the apex of the heart. The blood clots were removed and the chamber was washed with water in order to visualise the papillary muscles. The number, shape, position and pattern of the papillary muscles were noted and recorded. The method used in this study was comparable to that in the study of papillary muscles of the tricuspid valve complex by Skwarek et al, ${ }^{(1)}$ who based their classification of the papillary muscles on that set out earlier by Grochowski, ${ }^{(2)}$ which was enriched with different papillary muscle types not described previously. Skwarek et al had used the concepts of 'multi-apical' and 'multi-segmental' papillary muscles. ${ }^{(1)}$ In this study, papillary muscles that had a single base or a single apex were considered to be classical papillary muscles. Those with a single base and divided apex were categorised as multi-apical or multi-bellied, while papillary muscles with separate bases were considered multi-segmental or groups of papillary muscles.

\section{RESULTS}

The number of papillary muscles found in the series was highly variable. Instead of the usual two papillary muscles, many groups of papillary muscles were found. The classical picture of papillary muscles - the presence of two papillary muscles in the left ventricle - was found in only four (3.44\%) specimens (Fig. 1a). Two groups of papillary muscles were seen in $50(43.11 \%)$ specimens (Fig. 1b), three groups in 37 (31.90\%) specimens (Fig. 1c), and four groups in 25 (21.55\%) specimens (Fig. 1d). The variations in the number of papillary muscles are shown in Table I.

Various shapes of papillary muscles were observed as well conical (Fig. 2a), broad-apexed (Fig. 2b), pyramidal (Fig. 2c) and fan-shaped (Fig. 2d). The frequency of occurrence of these four

Department of Anatomy, Rural Medical College, Maharashtra, India

Correspondence: Sandhya Arvind Gunnal, Assistant Professor, Department of Anatomy, Rural Medical College, Loni, Rahata, Ahmednagar, Maharashtra 413736, India.sandhyagunnal@yahoo.com 

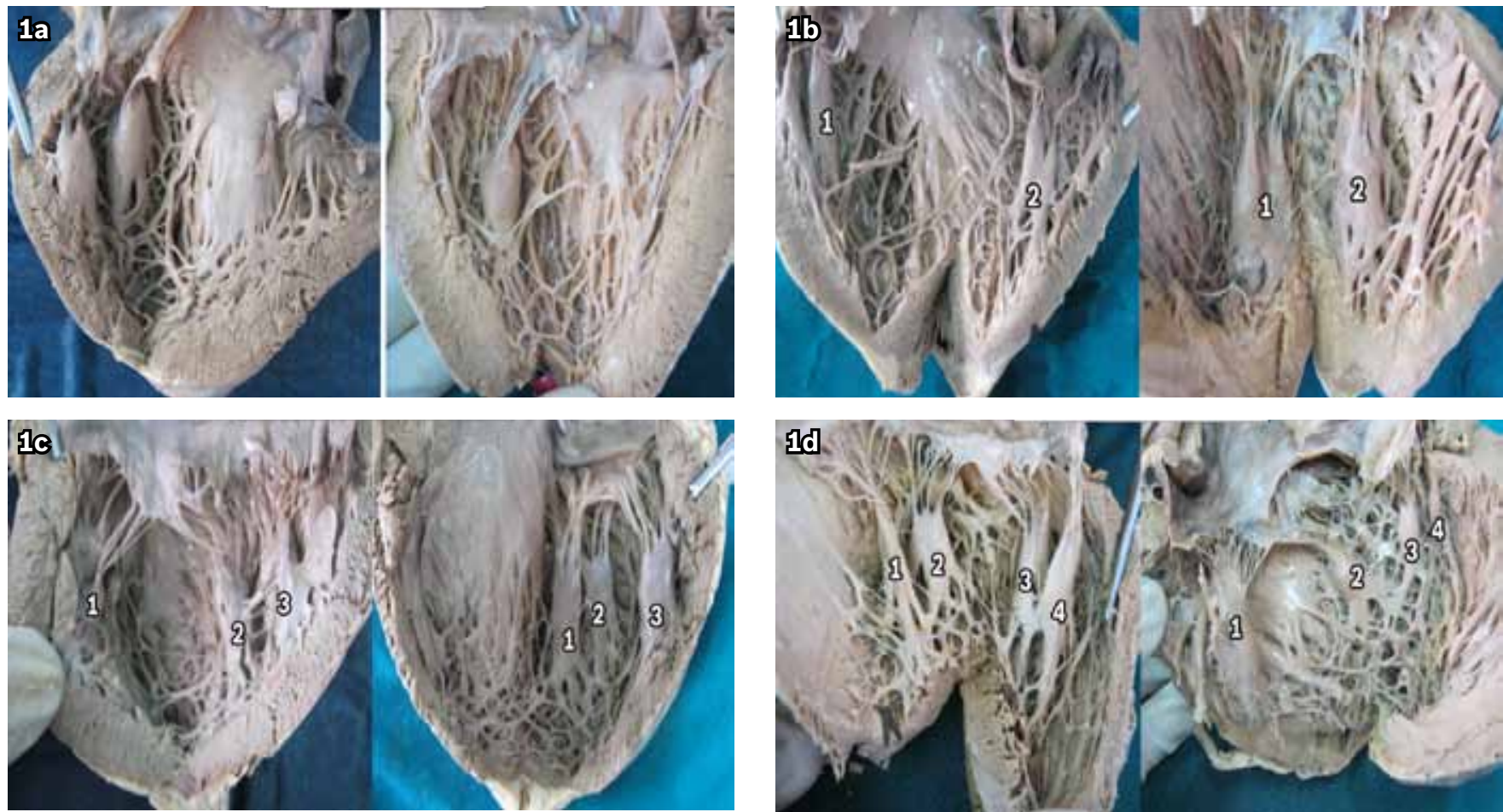

Fig. 1 Photographs show variations in the number of papillary muscles in the interior of the left ventricle. (a) Classical picture of two papillary muscles with a single base and a single apex; (b) Two groups of papillary muscles, depicted as 1 and 2 , with the right image showing the papillary muscles with multiple bellies; (c) Three groups of papillary muscles, depicted as 1, 2 and 3; (d) Four groups of papillary muscles, depicted as $1,2,3$ and 4

Table I. Variations in the number of papillary muscles.

\begin{tabular}{lc}
\hline No. of papillary muscles & No. of specimens (\%) \\
\hline Classical $^{*}$ & $4(3.44)$ \\
Two groups & $50(43.11)$ \\
Three groups & $37(31.90)$ \\
Four groups & $25(21.55)$ \\
\hline
\end{tabular}

${ }^{*}$ Two papillary muscles

shapes is shown in Table II. Additionally, we noted that there were papillary muscles with different shapes present in the same ventricle (Fig. 2e). Different patterns of papillary muscles were observed in the series. These included papillary muscles with 'separate bases and fused apex' (Fig. 3a), 'single base and divided apex' (Fig. 3b), 'small projections' of papillary muscles (Fig. 3c), long papillary muscles (Fig. 3d), 'perforated' papillary muscles (Fig. 3e) and those with 'base attached to a large bridge' (Fig. 3f). Table III shows the frequency of occurrence of the various patterns. The position of the papillary muscles was mostly at the middle third of the ventricular wall (95\%). In a few specimens, papillary muscles were seen in a small group deep to the cusps (5\%) in the upper third of the ventricular wall (Fig. 4).

\section{DISCUSSION}

The mitral valve complex is subjected to a greater degree of wear and tear due to the high pressure gradient across it, and in this respect, it is different from other valvular complexes. The disease processes affecting the mitral valvular complex assume a greater degree of significance because the cardiovascular physiology is affected to the extent of role played by the mitral valve complex.
Table II. Variations in the shapes of papillary muscles.

\begin{tabular}{lc}
\hline Shape of papillary muscles & No. of specimens (\%) \\
\hline Conical & $55(45.51)$ \\
Broad-apexed & $60(50.48)$ \\
Pyramidal & $31(26.73)$ \\
Fan-shaped & $15(12.93)$ \\
\hline
\end{tabular}

Note: Some specimens exhibited papillary muscles with more than one shape in each ventricle.

Table III. Variations in the patterns of papillary muscles.

\begin{tabular}{lc}
\hline Pattern of papillary muscles & No. of specimens (\%) \\
\hline Separate bases and fused apex & $25(21.55)$ \\
Single base and divided apex & $25(21.55)$ \\
Small projections of papillary muscles & $7(6.03)$ \\
Long papillary muscles & $2(1.72)$ \\
Perforated papillary muscles & $10(8.62)$ \\
Base attached to a large bridge & $3(2.58)$ \\
\hline
\end{tabular}

Note: The papillary muscles in some specimens did not conform to any particular pattern.

Thus, the mitral valve becomes the most common choice for research, but there are very few studies focusing on the morphology of the papillary muscle of the mitral valve complex. Victor and Nayak, who studied the variations in the papillary muscles of the normal mitral valve in 100 cases, state that the mitral valve apparatus, including the papillary muscles, is as unique to each individual as one's own fingerprints. ${ }^{(3)}$

Most textbooks of anatomy describe the presence of two papillary muscles in the left ventricle. Gray's Anatomy ${ }^{(4)}$ states that there are only two papillary muscles in the left ventricle 

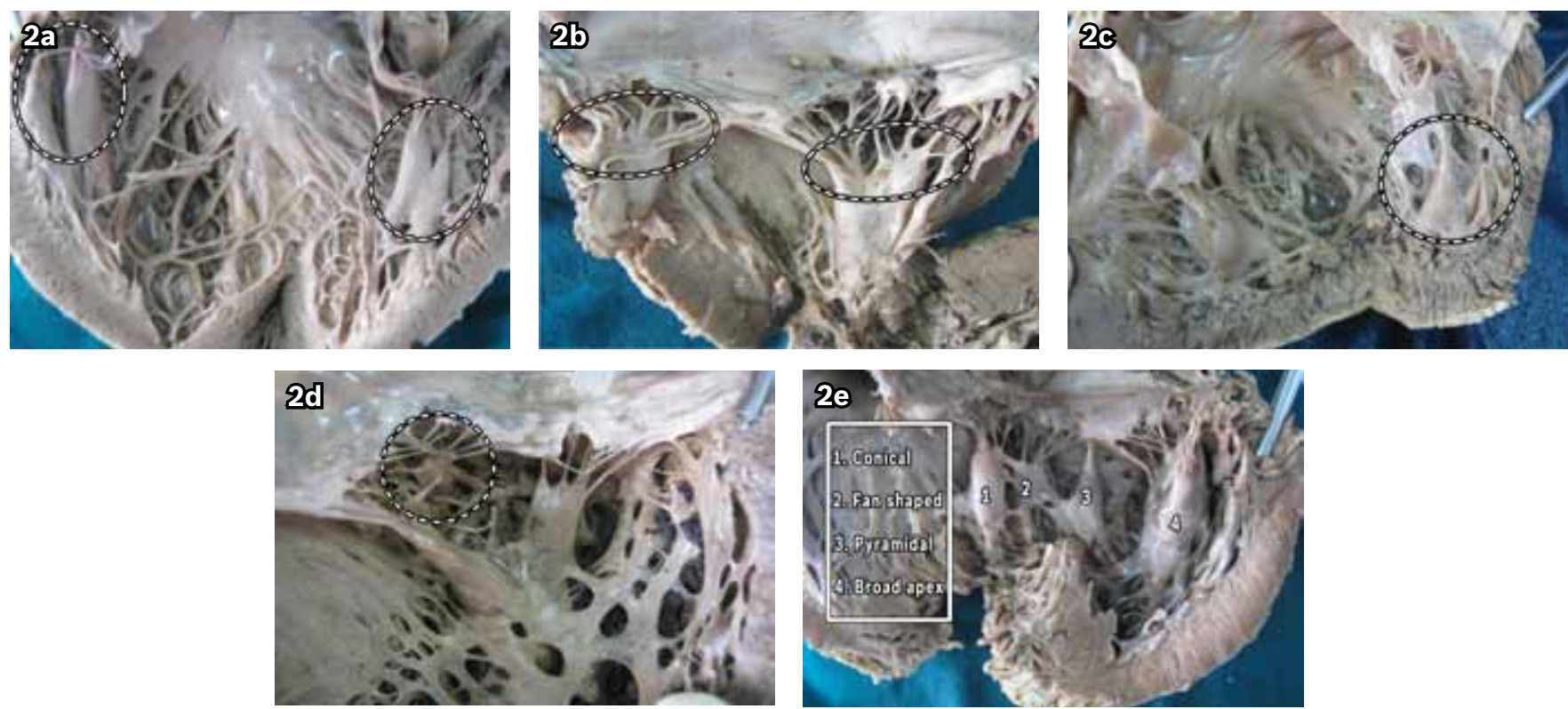

Fig. 2 Photographs show variations in the shape of papillary muscles in the interior of the left ventricle. (a) Conical; (b) Broad-apexed; (c) Fanshaped; (d) Pyramidal; (e) Various shapes in a single ventricle.
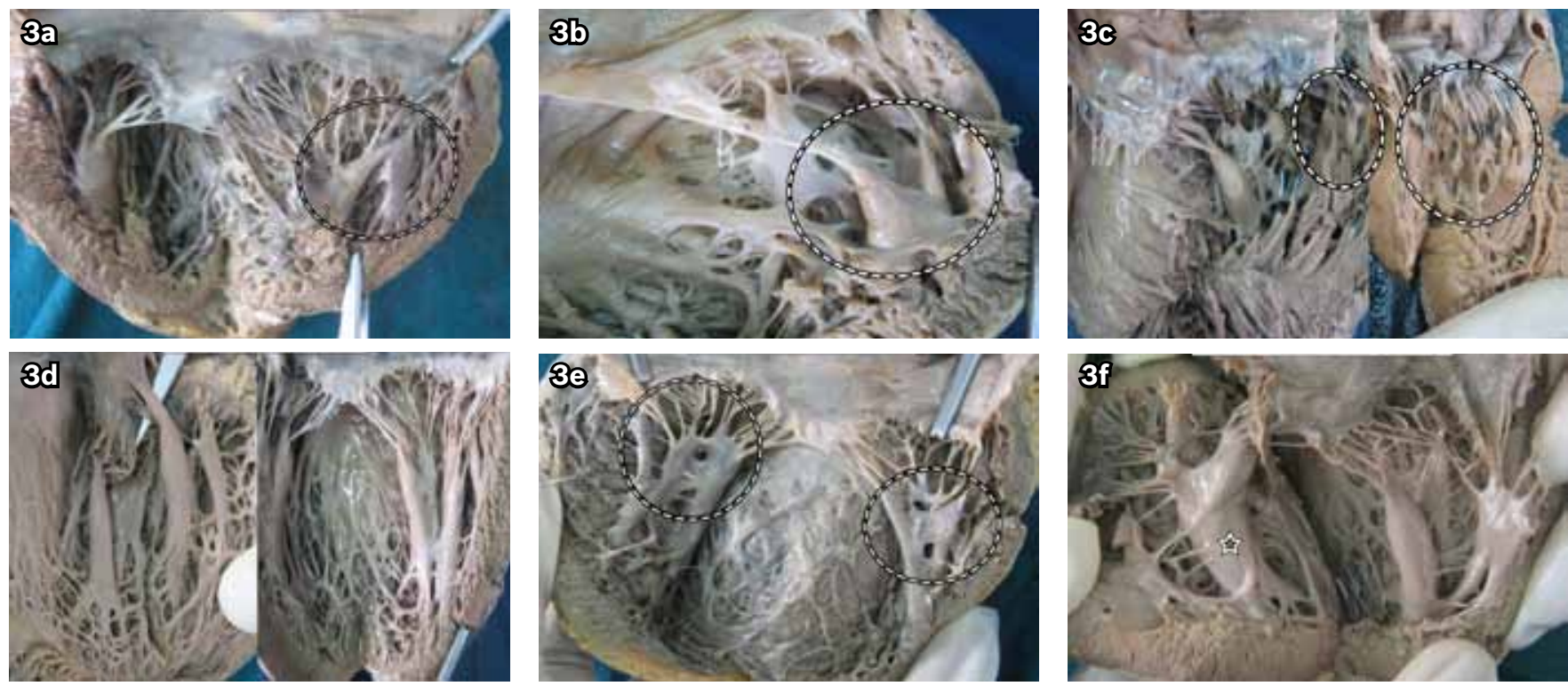

Fig. 3 Photographs show variations in the patterns of papillary muscles in the interior of the left ventricle. (a) Separate bases and fused apex; (b) Multiple bellied with a single base and divided apex; (c) Small projections of papillary muscles; (d) Long papillary muscles;

(e) Perforated papillary muscles; (f) Base of the papillary muscle attached to a large bridge.

- one large anterior papillary muscle and one small posterior papillary muscle. These papillary muscles may vary in length and breadth, and may be bifid. Ho's study on the anatomy of the mitral valve mentioned that there are usually groups of papillary muscles arranged fairly close together.(5) Oosthoek et al noted the presence of a third papillary muscle, ${ }^{\left({ }^{6}\right)}$ while Madu et al detected a third accessory papillary muscle closer to the apex in uncommon cases. ${ }^{(7)}$ Victor and Nayak found that intragroups interconnections are more frequent than intergroup interconnections, with the latter limited to the exchange of a few strands at the level of the chordae tendineae. ${ }^{(3)}$ In the present study, the presence of two papillary muscles with a 'single base and single apex' in the left ventricle was found in only $3.44 \%$ of the specimens, while two or more groups of papillary muscles were found in the rest of the cases.

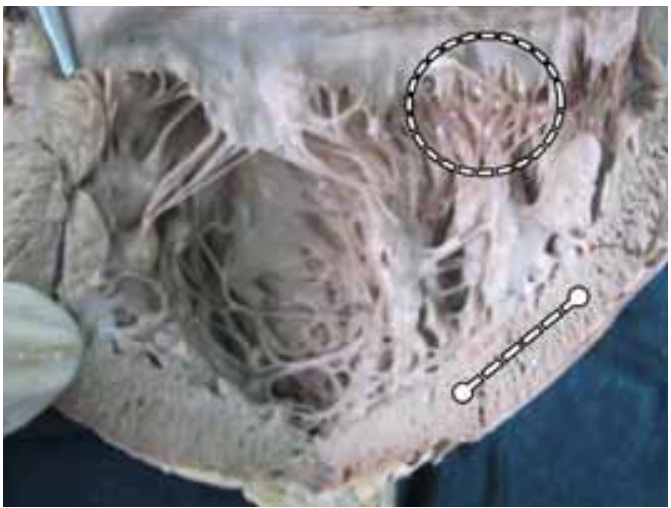

Fig. 4 Photograph shows the position of papillary muscles in the interior of the left ventricle. Most are seen in the middle third of the ventricular wall (line). A small group of papillary muscles is present deep to the cusps in the upper third of the ventricular wall (circle). 
An increased number and size of the papillary muscles, as well as their malformation, may cause left ventricular outflow tract obstruction and mitral regurgitation. In cases where there are only two papillary muscles in the left ventricle, half the chordae are under the control of one single papillary muscle. Thus, an ischaemic event affecting the base of the papillary muscle will render half the chordae dysfunctional, leading to mitral valve prolapse and severe mitral regurgitation. Myocardial infarction will not affect the functions of the mitral valve insofar as there are more papillary muscles that are in groups. This results in the group being partially affected, and consequently, fewer dysfunctional chordae.

The shape of the papillary muscles affects the passage of blood flow. Papillary muscles are usually described as conicalshaped in standard textbooks. In the present study, $45.51 \%$ of the specimens had conical-shaped papillary muscles. Other shapes found in the present study included broad-apexed, pyramidal and fan-shaped. The chances of left ventricular outflow tract obstruction are higher in hypertrophy of fan-shaped papillary muscles and papillary muscles with a broad apex. The papillary muscle that best facilitates cardiovascular physiology by posing minimum obstruction to blood flow is conical-shaped, broadbased, attached to the ventricular wall away from the centre of cavity and with a narrow apex occupying minimal space in the centre of the cavity. According to Victor and Nayak, the muscle belly comes in varied shapes, including conical, mammillated, flattopped, grooved, stepped, wavy, arched, sloped and saucerised. In cases where a group of papillary muscle with 2-5 muscle bellies occur, the authors have recorded various configurations such as two-tiered, interlinked, parallel, arched and $\mathrm{V}, \mathrm{Y}$ or $\mathrm{H}$ configurations. ${ }^{(3)}$ Papillary muscle realignment and repositioning is the treatment of choice for symptomatic left ventricular outflow tract obstruction and dysfunction. ${ }^{(6,8,9)}$

Midventricular obstruction is frequently caused by the anomalous insertion of a papillary muscle directly into the anterior mitral leaflet without interposition of the chordae tendineae. In our study, we found two such cases $(1.72 \%)$ of direct insertion of papillary muscle into the cusps without the intervening chordae tendineae. Papillary muscle resection is the usual treatment for midventricular obstruction. Maron et al have reported a novel extended myomectomy that includes the hypertrophic septal and papillary muscle to relieve the obstruction. ${ }^{(10)}$ In the present study, different patterns of papillary muscles were found in the specimens. Such differing patterns can be traced to embryological development. In the embryonic heart, papillary muscles develop from the trabecular myocardial ridge by a process of gradual delamination from the ventricular wall. If one or two papillary muscles fail delamination in the left ventricle, it results in asymmetry of the mitral valve. Incomplete delamination of the trabecular ridge in the left ventricle is responsible for variations in the morphological characteristics of the papillary muscles. ${ }^{(6)}$

We also noted in the present study that the papillary muscles were mostly positioned at the middle third of the ventricular wall
(95\%). In a few exceptions (5\%), the papillary muscles were seen in a small group deep to the cusps from the upper third of the ventricular wall. Ho's study states that these groups of papillary muscles arise from the apical and middle thirds of the left ventricular wall. ${ }^{(5)}$ According to Victor and Nayak, ${ }^{(3)}$ in the anterolateral group of papillary muscles, $19 \%$ of papillary muscle bellies arise from the upper third of the ventricle, $79.5 \%$ from the middle third and $1.5 \%$ from the lower third. Proper positioning of the papillary muscle, alignment of its chordae and the direction of tractions exerted on the cusp are of prime importance, from the standpoint of normal cardiovascular physiology.

In left ventricular dilatation, the papillary muscles are displaced, with alteration in the direction of pull and incomplete approximations, i.e. cusps fall short of each other, leading to mitral regurgitations. ${ }^{(11,12)}$ However, in a prolapsed mitral valve, there is an excess of movement (overlapping) of one cusp in relation to the other. Thus, the movement of the prolapsing leaflet is possibly dependent on the architecture and location of the papillary muscles nearest to the valve. Mitral valve complex repair is considered the gold standard of treatment for mitral regurgitation. The physical integrity and physiology of the mitral valve complex is restored with procedures such as chordal shortening, realignment, repositioning, reconstructions and resectioning. Anterior leaflet prolapse caused by elongated chordae can always be addressed with papillary muscle repositioning by bringing down the anterior head and fixing the prolapsed leaflet. ${ }^{(13)}$

Surgery for papillary muscle realignment is done using two or three mattress sutures with a pledget, passed through the base and body of the anterior and posterior papillary muscles. The sutures are then tied till both the papillary muscles come in contact with each other. ${ }^{(14)}$ Many studies have shown that variations in the morphology of papillary muscles are of significance in surgical procedures. ${ }^{(8,9,13,15)}$ In all surgical procedures, the two papillary muscles are stitched together to correct the disorder, or one of the heads of the anterior papillary muscle is resectioned and then stitched together with the posterior papillary muscle. If there are more papillary muscle bellies, as found in the present study, the number of options to decide the direction and degree of realignment also increases, thereby facilitating the restoration of normal physiological function.

In conclusion, we have found considerable variations in the number, shape, pattern and position of the papillary muscles in the present series. Our findings neither matched those of other previous studies nor were they similar to the descriptions given in standard textbooks. This may be due to the degree of variations. No two mitral valve complexes have the same architectural arrangement, as each case seems to be unique. In view of this, there is a clear need to conduct future large-scale studies in different regions of the world in order to investigate the reasons behind each specific pattern. With better understanding of the different architectural arrangements and the reasons thereof, cardiothoracic surgeons may be able to tailor the surgical 
procedure according to the papillary muscle pattern of the individual patient.

\section{REFERENCES}

1. Skwarek M, Hreczecha J, Grzybiak M, Kosiński A. Remarks on the morphology of the papillary muscles of the right ventricle. Folia Morphol (Warsz) 2005; 64:176-82.

2. Grochowski P. [Kształtowanie się mięśnia brodawkowatego tylnego w prawej komorze serca w rozwoju osobniczym człowieka] (dissertation). Gdańsk: Medical University of Gdansk, 2001. Russian.

3. Victor S, Nayak VM. Variations in the papillary muscles of the normal mitral valve and their surgical relevance. J Card Surg 1995; 10:597-607.

4. Standring S. Gray's Anatomy. 39th ed. Edinburgh: Elsevier Churchill Livingstone 2005, 1006-8.

5. Ho SY. Anatomy of the mitral valve. Heart 2002; 88 suppl 4:iv5-iv10.

6. Oosthoek PW, Wenink AC, Wisse LJ, Gittenberger-de Groot AC. Development of the papillary muscles of the mitral valve: morphogenetic background of parachute-like asymmetric mitral valves and other mitral valve anomalies. J Thorac Cardiovasc Surg 1998; 116:36-46.

7. Madu EC, D'Cruz IA. The vital role of papillary muscles in mitral and ventricular function: echocardiographic insights. Clin Cardiol 1997; 20:93-8.

8. Bryant R 3rd, Smedira NG. Papillary muscle realignment for symptomatic left ventricular outflow tract obstruction. J Thorac Cardiovasc Surg 2008; 135:223-4.

9. Yousefnia MA, Mandegar MH, Roshanali F, Alaeddini F, Amouzadeh F. Papillary muscle repositioning in mitral valve replacement in patients with left ventricular dysfunction. Ann Thorac Surg 2007; 83:958-63.

10. Maron BJ, Nishimura RA, Danielson GK. Pitfalls in clinical recognition and a novel operative approach for hypertrophic cardiomyopathy with severe outflow obstruction due to anomalous papillary muscle. Circulation 1998; 98:2505-8.

11. Ranganathan N, Burch GE. Gross morphology and arterial supply of the papillary muscles of the left ventricle of man. Am Heart J 1969; 77:506-16.

12. Roberts WC, Cohen LS. Left ventricular papillary muscles. Description of the normal and a survey of conditions causing them. Circulation 1972; 46:138-54.

13. Dreyfus GD, Souza Neto O, Aubert S. Papillary muscle repositioning for repair of anterior leaflet prolapse caused by chordal elongation. J Thorac Cardiovasc Surg 2006; 132:578-84.

14. Fumimoto K, Fukui T, Shimokawa T, Takanashi S. Papillary muscle realignment and mitral annuloplasty in patients with severe ischemic mitral regurgitation and dilated heart. Interact Cardiovasc Thorac Surg 2008; 7:368-71.

15. Kochi K, Okada K, Watari M, Orihashi K, Sueda T. Papillary muscle resection as a treatment for midventricular obstruction. Ann Thorac Cardiovasc Surg 2002; 8:109-11.

\section{SMA EVENTS FEBRUARY - JUNE 2013}

\begin{tabular}{|c|c|c|c|c|c|}
\hline DATE & EVENT & VENUE & CME POINTS & WHO SHOULD ATTEND? & CONTACT \\
\hline \multicolumn{6}{|c|}{ CME Activities } \\
\hline $\begin{array}{l}23 \text { February } \\
\text { Saturday }\end{array}$ & SMC Disciplinary Process and Sentencing & Gleneagles Hospital & TBC & $\begin{array}{l}\text { Doctors and Healthcare } \\
\text { Professionals }\end{array}$ & $\begin{array}{l}\text { Denise Tan } 62231264 \\
\text { denisetan@sma.org.sg }\end{array}$ \\
\hline $\begin{array}{l}9 \text { March } \\
\text { Saturday }\end{array}$ & $\begin{array}{l}\text { SMA Lecture } 2012 \text { - Euthanasia: } \\
\text { A Matter of Life or Death }\end{array}$ & $\begin{array}{l}\text { Sheraton Towers } \\
\text { Singapore }\end{array}$ & TBC & $\begin{array}{l}\text { Doctors and Healthcare } \\
\text { Professionals }\end{array}$ & $\begin{array}{l}\text { Denise Tan } 62231264 \\
\text { denisetan@sma.org.sg }\end{array}$ \\
\hline $\begin{array}{l}10 \text { March } \\
\text { Sunday }\end{array}$ & BCLS/CPR + AED Courses & $\begin{array}{l}\text { Singapore Heart } \\
\text { Foundation }\end{array}$ & 2 & Doctors and Clinic Staff & $\begin{array}{l}\text { Lin Shirong } 62231264 \\
\text { cpr@sma.org.sg }\end{array}$ \\
\hline $\begin{array}{l}16 \text { March } \\
\text { Saturday }\end{array}$ & SMA Workshop: Death Certification & Raffles Town Club & TBC & $\begin{array}{l}\text { Doctors and Healthcare } \\
\text { Professionals }\end{array}$ & $\begin{array}{l}\text { Denise Tan 62231264 } \\
\text { denisetan@sma.org.sg }\end{array}$ \\
\hline $\begin{array}{l}24 \text { March } \\
\text { Sunday }\end{array}$ & $\mathrm{BCLS} / \mathrm{CPR}+\mathrm{AED}$ Courses & $\begin{array}{l}\text { Singapore Heart } \\
\text { Foundation }\end{array}$ & 2 & Doctors and Clinic Staff & $\begin{array}{l}\text { Lin Shirong } 62231264 \\
\text { cpr@sma.org.sg }\end{array}$ \\
\hline $\begin{array}{l}7 \text { April } \\
\text { Sunday }\end{array}$ & $\mathrm{BCLS} / \mathrm{CPR}+\mathrm{AED}$ Courses & $\begin{array}{l}\text { Singapore Heart } \\
\text { Foundation }\end{array}$ & 2 & Doctors and Clinic Staff & $\begin{array}{l}\text { Lin Shirong } 62231264 \\
\text { cpr@sma.org.sg }\end{array}$ \\
\hline $\begin{array}{l}12 \text { May } \\
\text { Sunday }\end{array}$ & $\mathrm{BCLS} / \mathrm{CPR}+\mathrm{AED}$ Courses & $\begin{array}{l}\text { Singapore Heart } \\
\text { Foundation }\end{array}$ & 2 & Doctors and Clinic Staff & $\begin{array}{l}\text { Lin Shirong } 62231264 \\
\text { cpr@sma.org.sg }\end{array}$ \\
\hline $\begin{array}{l}26 \text { May } \\
\text { Sunday }\end{array}$ & BCLS/CPR + AED Courses & $\begin{array}{l}\text { Singapore Heart } \\
\text { Foundation }\end{array}$ & 2 & Doctors and Clinic Staff & $\begin{array}{l}\text { Lin Shirong } 62231264 \\
\text { cpr@sma.org.sg }\end{array}$ \\
\hline $\begin{array}{l}9 \text { June } \\
\text { Sunday }\end{array}$ & BCLS/CPR + AED Courses & $\begin{array}{l}\text { Singapore Heart } \\
\text { Foundation }\end{array}$ & 2 & Doctors and Clinic Staff & $\begin{array}{l}\text { Lin Shirong } 62231264 \\
\text { cpr@sma.org.sg }\end{array}$ \\
\hline $\begin{array}{l}30 \text { June } \\
\text { Sunday }\end{array}$ & BCLS/CPR + AED Courses & $\begin{array}{l}\text { Singapore Heart } \\
\text { Foundation }\end{array}$ & 2 & Doctors and Clinic Staff & $\begin{array}{l}\text { Lin Shirong } 62231264 \\
\text { cpr@sma.org.sg }\end{array}$ \\
\hline
\end{tabular}

Non-CME Activities

22 February

Friday

Lawyers-Doctors Networking Session

TBC

NA

SMA Members

Azliena Samhudi 62231264 membership@sma.org.sg

Look out for more exciting events coming your way in the next few months! 